\title{
Increasing the Lateral Line Length of Drip Irrigation Systems
}

\author{
Rafael Ludwig ${ }^{1^{*}}$ and João Carlos Cury Saad ${ }^{1 *}$ \\ ${ }^{1}$ College of Agricultural Sciences, UNESP - São Paulo State University. 1780, José Barbosa \\ de Barros, 18607-037, Botucatu, SP, Brazil.
}

Authors' contributions

This work was carried out in collaboration between all authors. All authors read and approved the final manuscript.

Research Article

Received $11^{\text {th }}$ November 2012

Accepted $28^{\text {th }}$ June 2013

Published $15^{\text {th }}$ September 2013

\section{ABSTRACT}

Aims: The hypothesis of this research is that it is possible to increase the drip irrigation lateral line length by using a larger spacing between emitters at the beginning of the lateral line and a smaller one after a certain distance, which would allow for a higher pressure variation along the lateral line under an acceptable value of distribution uniformity.

Study Design: Non-pressure compensating drip hose is widely utilized for vegetables and orchards irrigation. Though there is a limitation, which is the lateral line length must be short to maintain uniformity due to head loss and slope, any procedure to increase the length is appropriate because it represents low initial cost of the irrigation system.

Place and Duration of Study: This study was conducted at the College of Agricultural Sciences of Sao Paulo State University in Botucatu, SP, during the year 2011.

Methodology: To evaluate this hypothesis, a nonlinear programming model (NLP) was developed. The input data were: diameter, roughness coefficient, pressure variation, emitter operational pressure, relationship between emitter discharge and pressure. The output data were: line length, discharge and length of the each section with different spacing between drippers, total discharge in the lateral line, multiple outlet adjustment coefficient, head losses, localized head loss, pressure variation, number of emitters, spacing between emitters, discharge in each emitter, and discharge per linear meter. 
Results: The mathematical model developed was compared with the lateral line length obtained with the algebraic solution generated by the Darcy-Weisbach equation. The NLP model showed the best results since it generated a greater gain in the lateral line length, maintaining the uniformity and the flow variation under acceptable standards. It also had lower flow variation.

Conclusion: NLP model showed the best results when compared with the conventional procedure, generating gain in the lateral line length, keeping the uniformity and flow variation under acceptable standards.

Keywords: Emitter spacing; trickle irrigation; emission uniformity; optimization.

\section{INTRODUCTION}

In drip irrigation systems water is applied directly in the root system region, with high efficiency, but this system has the disadvantage of possible emitters clogging and its installation cost is high [1]. Basically, the emitters can be compensating or nonpressure compensating. The compensating drippers provide constant flow rate under pressure variations along the lateral line, allowing longer lengths but, they are more expensive. Using non-pressure compensating emitters, the flow rate decreases as the pressure is reduced, resulting in shorter lateral lines in order to obtain the desired uniformity. Non-pressure compensating drip hose is widely used for vegetables and orchards irrigation. The limitation of this emitter is that the lateral line length must be short to maintain uniformity due to head loss and slope.

It is important to study procedures and criteria to obtain longer lateral lines when using nonpressure compensating emitters. It is possible to extend the lateral line length using two emitters spacing in different sections [2]. In this case, the system design consists in the determination of the two emitters spacing utilized and the changing point between spacing. It is assumed that the spacing changing point would be at $40 \%$ of the total length, because this is approximately the average location [3]. For practical purposes, the average pressure is located at $40 \%$ of the lateral line length and at this point $75 \%$ of total head loss (hf) has already been consumed [4]. However, this arbitrary criterion does not necessarily ensure the best solution.

The use of a $30 \%$ flow variation $(\Delta q)$ was proposed [5] and it was found that this value resulted in distribution uniformity over $80 \%$. With the non-pressure compensating emitters, the design usually adopted a flow variation $(\Delta \mathrm{q})$ of $10 \%$ and a corresponding pressure variation $(\Delta \mathrm{H})$ of $20 \%$, allowing uniformity distribution between 95 and $98 \%[5,4]$. To evaluate the irrigation uniformity two indicators can be used: distribution uniformity (DU) which is the ratio between the average of lower $25 \%$ of flow values and the average, expressed as a percentage [6,7] and the emission uniformity (EU), which considers the emitters characteristics and the hydraulic configuration of the drip irrigation subunit [8].

Longer lateral lines in drip irrigation systems using conventional drippers provide cost reduction, but it is necessary to obtain irrigation uniformity [2]. Utilizing higher $\Delta q$ levels can provide longer lateral lines.

The design should be optimized and it can be obtained with the use of mathematical optimization models based on operations research techniques, as it is the case of Nonlinear Programming (NLP). 
Maximizing the lateral line length with two spacing and defining the spacing changing point are typically an optimization problem, but it can be characterized and solved by a nonlinear programming model.

This study aimed to evaluate the possibility of increasing the lateral line length of an irrigation system using non-pressure compensating drip hose with different spacing between emitters but maintaining irrigation uniformity at appropriate levels. For this, a comparison was carried out between the NLP model and the conventional design procedure.

\section{METHODOLOGIES}

A mathematical model using Nonlinear Programming was developed for comparison with the conventional methodology to determine the lateral line maximum length, which is based on the Darcy-Weisbach equation.

\subsection{Objective Function of Model}

The developed model objective function is the total lateral length maximization using two spacing in different sections as described in the objective function (eq. 1).

$$
\operatorname{MAX} \quad L=L_{1}+L_{2}
$$

where:

$$
\begin{array}{ll}
L & =\text { lateral line total length }(m) ; \\
L_{1} & =\text { first section length }(m) ; \\
L_{2} & =\text { second section length }(m) .
\end{array}
$$

\subsection{Model Constraints}

\subsubsection{Pressure head variation}

For each section the model provides a pressure variation (eq. 2 and 3 ) and the sum (eq. 4) of them must be equal to the $\Delta \mathrm{h}$ informed on the input data.

$$
\begin{aligned}
& h f_{1}=H \quad \Delta H_{1} \\
& h f_{2}=H \quad \Delta H_{2} \\
& \Delta H=\Delta H_{1}+\Delta H_{2}
\end{aligned}
$$

where:

$$
\begin{array}{ll}
\mathrm{hf}_{1} & =\text { head loss in the section } 1 ; \\
\mathrm{hf}_{2} & =\text { head loss in the section } 2 \\
\Delta \mathrm{H}_{1} & =\text { pressure variation in the section } 1 ; \\
\Delta \mathrm{H}_{2} & =\text { pressure variation in the section } 2 ; \\
\Delta \mathrm{H} & =\text { pressure variation informed on the input data. }
\end{array}
$$


Head loss in each section is also estimated using Hazen-Williams equation and multiple outlet adjustment coefficients, as showed by equations 5 and 6 .

$$
\begin{aligned}
& h f_{1}=\left(\frac{10.646 Q_{t}^{1.85} C^{1.85}\left(L_{1}+L_{2}\right)}{D^{4.87} F_{t}}\right)-\left(\frac{10.646 Q_{2}^{1.85} L_{2} F_{2}}{C^{1.85} D^{4.87}}\right) \\
& h f_{2}=\left(\frac{10.646 Q_{2}^{1.85} L_{2} F_{2}}{C^{1.85} D^{4.87}}\right) \\
& Q_{t}=Q_{1}+Q_{2}
\end{aligned}
$$

where:

$$
\begin{array}{ll}
Q_{t} & =\text { total lateral line discharge }\left(\mathrm{L} \mathrm{h}^{-1}\right) ; \\
\mathrm{Q}_{1} & =\text { first section discharge }\left(\mathrm{L} \mathrm{h}^{-1}\right) ; \\
\mathrm{Q}_{2} & =\text { second section discharge }\left(\mathrm{L} \mathrm{h}^{-1}\right) ; \\
\mathrm{F}_{\mathrm{t}} & =\text { multiple outlet adjustment coefficient for the total lateral line; } \\
\mathrm{F}_{2} & =\text { multiple outlet adjustment coefficient for the second section; } \\
\mathrm{C} & =\text { Friction coefficient (Hazen-Williams equation); } \\
\mathrm{D} & =\text { internal diameter of pipe, } \mathrm{m}
\end{array}
$$

Christiansen multiple outlet adjustment coefficients $(F)$ is given by:

$$
F=\frac{1}{m+1}+\frac{1}{2 N}+\frac{\sqrt{m-1}}{6 N^{2}}
$$

where:

$$
\begin{array}{ll}
\mathrm{m} & =\text { discharge exponent in the friction loss equation; } \\
\mathrm{N} & =\text { total number of outlets. }
\end{array}
$$

From equation 8 it was possible to calculate the Christiansen adjustment factor to the total length of lateral line $\left(F_{t}\right)$ and to the second section $\left(F_{2}\right)$ using the total number of emitters in the lateral line and the emitters number in the second section, respectively.

\subsubsection{Discharge}

The emitter flow can be characterized empirically as a function of the operational pressure, according to equation 9 [10 and 11].

$$
q=K H^{x}
$$

where:

$$
\begin{array}{ll}
\mathrm{q} & =\text { emitter flow }\left(\mathrm{L} \mathrm{h}^{-1}\right) \\
\mathrm{K} & =\text { proportionality factor; } \\
\mathrm{H} & =\text { emitter pressure, water column in meters (m.c.a); } \\
\mathrm{X} & =\text { exponent of flow which characterizes the flow regime. }
\end{array}
$$


The emitter discharge was calculated at three different points using the equation 9 and the respective pressure in each point. The first one is located at lateral line inlet (eq. 10), the second is at the transition point (eq.11) between the spacing and the third is at the end of line (eq. 12). The average discharge in each section is given by equations 13 e 14 .

$$
\begin{aligned}
q_{e} & =K H^{x} \\
q_{\mathrm{int}} & =K\left(H-h f_{1}\right)^{x} \\
q_{\mathrm{int}} & =K\left[H-\left(h f_{1}+h f_{2}\right)\right]^{x} \\
q_{L 1} & =\left(\frac{q_{e}+q_{\mathrm{int}}}{2}\right) \\
q_{L 2} & =\left(\frac{q_{\mathrm{int}}+q_{f}}{2}\right)
\end{aligned}
$$

where:

$\mathrm{q}_{\mathrm{e}}=$ discharge at the lateral line inlet

$\mathrm{q}_{\text {int }}=$ discharge at the transition point between sections with different the spacings

$q_{f}=$ discharge at the end of the lateral line

$\mathrm{q}_{\mathrm{L} 1}=$ average discharge in the section 1

$\mathrm{q}_{\mathrm{L} 2}=$ average discharge in the section 2

\subsubsection{Discharge per linear meter}

The discharge per meter linear is given by equations 15 and 16 .

$$
\begin{aligned}
& q_{\text {unit } 1}=\frac{q_{L 1} N_{1}}{L_{1}} \\
& q_{\text {unit } 2}=\frac{q_{L 2} N_{2}}{L_{2}} \\
& N_{1}=\frac{L_{1}}{S e_{1}} \\
& N_{2}=\frac{L_{2}}{S e_{2}} \\
& Q_{1}=q_{L 1} N_{1} \\
& Q_{2}=q_{L 2} N_{2}
\end{aligned}
$$

where: 
$q_{\text {unit } 1}=$ discharge per meter in the section 1

$q_{\text {unit2 }}=$ discharge per meter in the section 2

$\mathrm{N}_{1}=$ number of emitters in the section 1

$\mathrm{N}_{2}=$ number of emitters in the section 2

$\mathrm{Se}_{1}=$ emitter spacing in section $1, \mathrm{~m}$

$\mathrm{Se}_{2}=$ emitter spacing in section $2, \mathrm{~m}$

\subsection{Input Data}

As an example a commercial non-pressure compensating drip hose was adopted, the characteristics are shown in Table 1.

Table 1. Non-pressure compensating drip hose characteristics

\begin{tabular}{ll}
\hline Parameters & Values \\
\hline Service pressure (m.c.a.) & 10 \\
Minimum pressure (m.c.a.) & 6 \\
Pipeline diameter $(\mathrm{mm})$ & 16 \\
K coefficient (eq. 1) & 0.46297 \\
Exponent $(\mathrm{x})$ - eq. 1 & 0.503 \\
Emitter coefficient of manufacturing variation $\left(\mathrm{C}_{\mathrm{vf}}\right)$ & 0.0353 \\
\hline
\end{tabular}

The data used in the calculations are shown in Table 2. As the model in GAMS $^{\circledR}$ uses nonlinear equations, the definition of the allowable variation of some variables is necessary in order to avoid division by zero during the calculations (Table 3).

Table 2. Input data for the GAMS developed model

\begin{tabular}{ll}
\hline Parameters & Valor \\
\hline Diameter (mm) & 16 \\
Friction coefficient (Hazen-Williams equation) & 140 \\
Pressure variation (\%) & 20 and 40 \\
Inlet pressure (m.c.a.) & 10 \\
\hline
\end{tabular}

Table 3. Range of variables used in the Gams model

\begin{tabular}{lll}
\hline Variable (by section) & Lower limit & Upper limit \\
\hline Discharge $\left(\mathrm{m}^{3} \mathrm{~s}^{-1}\right)$ & $2.78 \times 10^{-07}$ & $2.78 \times 10^{-04}$ \\
Lateral line section length $(\mathrm{m})$ & 1 & 1000 \\
Multiple outlet adjustment coefficient & 0.3 & 1 \\
Dripper number & 1 & 10000 \\
Dripper spacing $(\mathrm{m})$ & 0.1 & 1 \\
Discharge per linear meter $\left(\mathrm{m}^{3} \mathrm{~s}^{-1}\right)$ & $8.33 \times 10^{-0 \prime}$ & $1.39 \times 10^{-06}$ \\
\hline
\end{tabular}

The model provides several output data: lateral line total length, flow and length of each lateral line section with different spacing between emitters, total number of emitters, emitter spacing, flow rate per linear meter, head loss, pressure variation, multiple outlet adjustment coefficient, discharge in each emitter, and emitter average discharge. 
The NLP model was compared with the conventional procedure for lateral line length estimation from the head loss equation of head loss. In the case of non-compensating emitters used in orchards, the lateral lines works on level. Thus, any pressure variation is due to the total head loss (in the pipeline and located in the emitters). The lateral line diameter adopted in this study is $16 \mathrm{~mm}$, the most used commercially. Thus, the lateral line length becomes the only variable to be defined.

For the conventional procedure, the lateral line length was calculated by equation 26 , which is basically the combination of Darcy-Weisbach equation [3] and Blasius equation (eq. 24).

$$
\begin{aligned}
& h f=\frac{8 f L Q^{2}}{\pi^{2} D^{5} g} \\
& Q=\frac{q \cdot L}{S e} \\
& \mathrm{R}_{\mathrm{e}}=1,26 \times 10^{6} \frac{Q}{D} \\
& f=0,3164 \mathrm{Re}^{-0,25} \\
& h f^{\prime}=h f F \\
& L=\left(\frac{1281.11650554 h f^{\prime} S e^{1.75} D^{4.75}}{q^{1.75} F^{1 / 2.75}}\right)^{1 / 2}
\end{aligned}
$$

where:

hf' = total head loss in the lateral line with multiple outlets;

$\mathrm{Re}=$ Reynolds number

$\mathrm{Se}=$ emitter spacing, $\mathrm{m}$

$q=$ emitter discharge $\left(L h^{-1}\right)$;

To compare the NLP model and the conventional procedure two pressure variations were used: 20 and $40 \%$.

\section{RESULTS AND DISCUSSION}

The NLP model allowed the lateral line design to use two sections with different spacing. The conventional method calculated the lateral line to a single spacing between drippers $(0.4$ $\mathrm{m})$.

The emitter average flow was located at 37.85 and $38.64 \%$ of the lateral line length, with head loss until this point of 73.61 and $75.20 \%$ of the total lateral line head loss for the pressure variation of 20 and $40 \%$, respectively (Table 4 ). These values are consistent with those found by [4]. 
Table 4. Average flow location and head loss until the average flow location for the evaluated procedures and pressure variations

\begin{tabular}{lllll}
\hline $\begin{array}{l}\Delta \mathbf{H} \\
(\%)\end{array}$ & $\begin{array}{l}\text { GAMS }^{(} \\
\begin{array}{l}\text { Average flow } \\
\text { location } \\
(\% \text { of } \mathrm{L})\end{array}\end{array}$ & $\begin{array}{l}\text { Cumulative head loss } \\
\text { at average flow } \\
\text { location } \\
\text { (\% of total head loss) }\end{array}$ & $\begin{array}{l}\text { Conventional } \\
\begin{array}{l}\text { Average flow } \\
\text { location } \\
(\% \text { of } \mathrm{L})\end{array}\end{array}$ & $\begin{array}{l}\text { Cumulative head } \\
\text { loss at average } \\
\text { flow location (\% of } \\
\text { total head loss) }\end{array}$ \\
\hline 20 & 38.64 & 74.10 & 37.92 & 74.47 \\
40 & 37.85 & 73.61 & 38.10 & 75.20 \\
\hline
\end{tabular}

The $\Delta \mathrm{H}$ and the found $\Delta \mathrm{q}$ values were the same as those obtained by [12]; it was suggested that $\Delta \mathrm{q}$ can be related to $\Delta \mathrm{H}$, to obtain $\Delta \mathrm{H}$ of 20 and $40 \%, \Delta \mathrm{q}$ must be of 10 and $22 \%$, respectively (Table 5).

Table 5. Total length (L), discharge (Q), distribution uniformity (DU), emission uniformity $(E U)$, flow variation per meter $(\Delta \mathrm{ql})$ and flow variation $(\Delta \mathrm{q})$ for the pressure variation of 20 and $40 \%(\Delta \mathrm{H})$

\begin{tabular}{llllllll}
\hline Method & $\Delta \mathbf{H}(\mathbf{\%})$ & $\mathbf{L}(\mathbf{m})$ & $\mathbf{Q}\left(\mathbf{L ~ \mathbf { ~ } ^ { - 1 }}\right)$ & $\mathbf{D U}(\mathbf{\%})$ & $\mathbf{E U ~ ( \% )}$ & $\Delta \mathbf{q l} \mathbf{( \% )}$ & $\Delta \mathbf{q} \mathbf{( \% )}$ \\
\hline NLP & 20 & 152.04 & 454.07 & 96.98 & 92.58 & 8.71 & 10.87 \\
model & 40 & 194.43 & 575.68 & 93.04 & 88.72 & 18.40 & 22.82 \\
\hline Conventi & 20 & 130.80 & 450.02 & 97.50 & 93.09 & 9.02 & 9.02 \\
onal & 40 & 168.00 & 543.12 & 95.04 & 90.69 & 16.72 & 16.72 \\
\hline
\end{tabular}

The use of higher pressure variation $(40 \%)$ when compared to lower pressure variation $(20 \%)$ in the lateral line, showed a lower distribution uniformity, a lower emission uniformity, a higher emitters flow variation, and a greater discharge variation per linear meter (Table 5). However, for the NLP model the length gain was of $42.39 \mathrm{~m}$, compared to the $\Delta \mathrm{H} 20 \%$, and keeping the $\Delta q$ and the DU values within the limits offered by [5].

Comparing the NLP model to the conventional procedure, it was found that the DU had difference of $2 \%$ (for $40 \% \Delta \mathrm{H}$ ) and $0.52 \%$ (for $20 \% \Delta \mathrm{H}$ ). The difference in the EU was $1.97 \%$ (for $40 \% \Delta \mathrm{H}$ ) and $0.5 \%$ (for $20 \% \Delta \mathrm{H}$ ). The variation in flow rate per meter showed a difference of $0.31 \%(20 \% \Delta \mathrm{H})$ and $1.68 \%(40 \% \Delta \mathrm{H})$. The lowest flow variation per linear meter was found using $\mathrm{GAMS}^{\circledR}$ and $\Delta \mathrm{H}$ of $20 \%$.

Comparing the uniformity indexes, the EU showed lower values compared to DU, however, the values were higher than $88 \%$ (Table 5). The reason the EU is more restrictive is because it considers the lowest discharge value while the DU considers the average $25 \%$ lower flow values in the lateral line or subunit.

The values obtained for the emitter number, lateral line length, and total evaluated flow for the $\Delta \mathrm{H}$ are shown in Table 6 . The conventional procedure showed a lower lateral line length than the NLP model. 
Table 6. Inlet pressure (H ent.), pressure at the end of lateral line ( $\mathrm{H} \mathrm{fim.),} \mathrm{emitter}$ spacing (Esp.), number of dripper, lateral line length (L), and lateral line initial discharge (Q)

\begin{tabular}{|c|c|c|c|c|c|c|c|c|c|c|c|}
\hline \multirow[t]{2}{*}{ Model } & \multirow[t]{2}{*}{$\begin{array}{l}\Delta \mathbf{H} \\
(\%)\end{array}$} & \multirow{2}{*}{$\begin{array}{l}\text { Initial } \\
\text { pressure } \\
\text { (m.c.a) }\end{array}$} & \multirow{2}{*}{$\begin{array}{l}\text { Final } \\
\text { pressure } \\
\text { (m.c.a) }\end{array}$} & \multicolumn{2}{|c|}{ Spacing (m) } & \multicolumn{2}{|c|}{$\begin{array}{l}\text { Numbers } \\
\text { drip }\end{array}$} & \multicolumn{3}{|l|}{$L(m)$} & \multirow[t]{2}{*}{$\begin{array}{l}\mathbf{Q} \\
\left(L^{-1}\right)\end{array}$} \\
\hline & & & & Initial & Final & Initial & Final & Initial & Final & Total & \\
\hline NLP & 20 & 10 & 8.00 & 0.47 & 0.44 & 144 & 190 & 67.68 & 84.36 & 152.04 & .07 \\
\hline & 4 & 10 & & 0.4 & 0.3 & 201 & 268 & 89.65 & 104.79 & & \\
\hline & $\begin{array}{l}20 \\
40\end{array}$ & $\begin{array}{l}10 \\
10\end{array}$ & $\begin{array}{l}8.29 \\
6.95\end{array}$ & 0.40 & & $\begin{array}{l}327 \\
420\end{array}$ & & & & & $\begin{array}{l}450.02 \\
543.12\end{array}$ \\
\hline
\end{tabular}

Emitter spacing obtained in the NLP model was between 0.39 and $0.47 \mathrm{~m}$ (Table 6). In all situations the obtained spacing in the initial section was higher than in the one in the final section, because this is necessary to maintain the flow rate per meter. As the pressure decreases along the lateral line, the emitter discharge also decreases and the model select a smaller spacing for the second section aiming to keep the flow rate per meter uniform in the lateral line.

In the NLP model, the first section were at 44.51 and $46.11 \%$ of $\mathrm{L}$, and at these points 80.55 and $82.61 \%$ of the total head loss were consumed, considering the $\Delta \mathrm{H}$ equal to 20 and $40 \%$ respectively.

The NLP model was developed to design the lateral line while optimizing the length using different spacing and assuring a uniform discharge per linear meter. This can be seen in Figs. 1 and 2 for the $\Delta \mathrm{H}$ equal to 20 and $40 \%$, respectively. In the spacing changing point, the discharge per linear meter modified from 2.87 to $3.03 \mathrm{~L}$. $\mathrm{h}^{-1} \mathrm{~m}^{-1}$ and from 2.7 to $3.07 \mathrm{~L}$. $\mathrm{h}^{-}$ ${ }^{1} \mathrm{~m}^{-1}$ for the pressure variation of 20 and $40 \%$, respectively. The highest discharge per linear meter occurred in the beginning of the lateral line, 3.14 (to $20 \% \Delta \mathrm{H}$ ) and $3.29 \mathrm{~L}^{-1} \mathrm{~h}^{-1} \mathrm{~m}^{-1}$ (to $40 \% \Delta \mathrm{H}$ ) and the lowest values occurred at the spacing changing point. At the end of lateral line, the discharges per linear meter were of 2.97 and $2.92 \mathrm{~L} . \mathrm{h}^{-1} \mathrm{~m}^{-1}$ for $\mathrm{a} \Delta \mathrm{H}$ of 20 and $40 \%$, respectively.

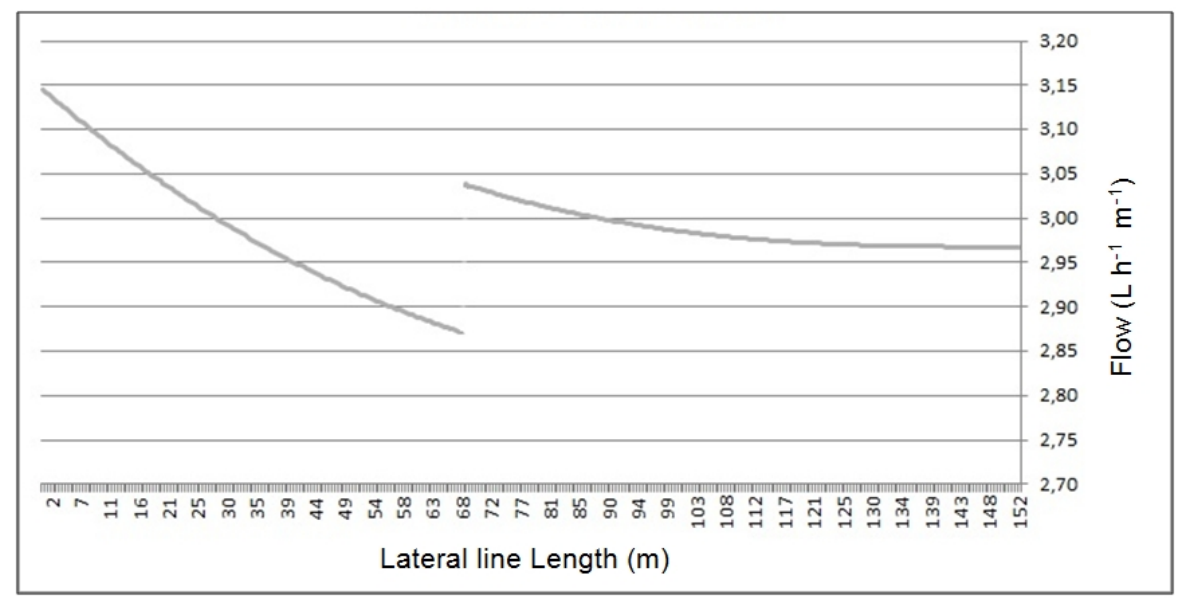

Fig. 1. Discharge per linear meter as a function of the lateral line length, for the $20 \%$ pressure variation 


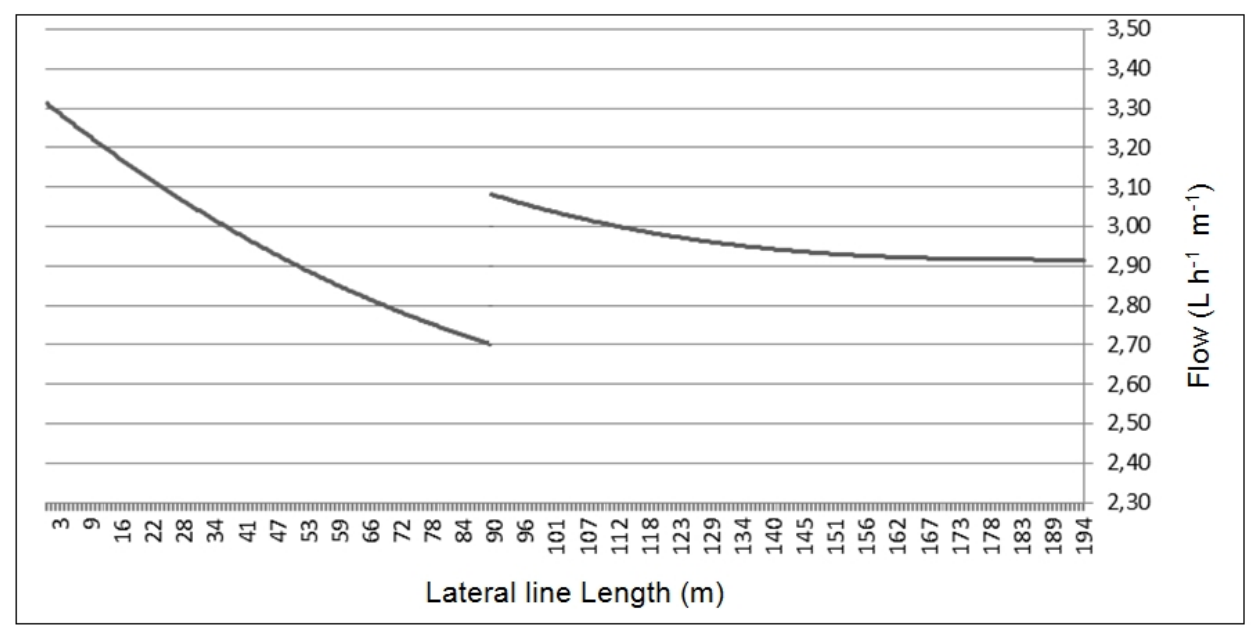

Fig. 2. Discharge per linear meter as a function of the lateral line length, for the $40 \%$ pressure variation

The longest lateral line was obtained with the NLP model. The use of higher pressure variation resulted in longer lateral lines and maintained the uniformity under acceptable standards. The adoption of two spacing in the same lateral line showed advantages compare to a single one.

In NLP model even with the lateral line showing higher $\Delta \mathrm{q}$ and $\Delta \mathrm{ql}$, the DU was under acceptable standards (over 93\%). The system low cost implementation was the result of the lateral line increase.

\section{CONCLUSIONS}

The initial hypothesis that the adoption of two emitters spacing would increase the lateral line length was confirmed. For 20 and $40 \%$ pressure variations it was obtained a length gain of 16.2 and $15.7 \%$, respectively, in the NLP model compared to the conventional method that uses a single spacing.

The spacing changing ideal location was approximately $45 \%$ of the total lateral line length. Using high flow variations under acceptable uniformity standards allowed the best results. NLP model showed the best results when compared to the conventional procedure by increasing the lateral line length and keeping the uniformity plus flow variation under acceptable standards.

\section{ACKNOWLEDGEMENTS}

The authors thank CNPq - Conselho Nacional de Desenvolvimento Científico e Tecnológico for the financial support.

\section{COMPETING INTERESTS}

Authors have declared that no competing interests exist. 


\section{REFERENCES}

1. Mantovani EC, Bernardo S, Palaretti IF. Irrigação: princípios e métodos. 3th ed. Viçosa: UFV. Portuguese; 2009.

2. Azevedo LP de; Saad JCC. Uso de dois espaçamentos entre gotejadores na mesma linha lateral e seus efeitos sobre a formação do bulbo molhado no solo e parâmetros físicos do rabanete. Irriga - Brazilian Journal of Irrigation and Drainage. 2012:17(2):148-167.

3. Keller J, Bliesner RD. Sprinkle and trickle irrigation. Caldwell: Blackburn Press; 1990.

4. Talens JAM. Riego localizado y fertirrigacion. Madrid: Mundi-Prensa. Spanish; 2002.

5. Wu IP. An assessment of hydraulic design of micro-irrigation systems. Agricultural Water Management. 1997:32(3):275-284.

6. Clemmens AJ, Solomon KH. Estimation of Global Irrigation Distribution Uniformity. Journal of Irrigation and Drainage Engineering. 1997;123(6):454-461.

7. Styles SW, et al. Accuracy of Global Microirrigation Distribution Uniformity Estimates. Journal of Irrigation and Drainage Engineering. 2008;134(3):292-297.

8. Saad JCC, Marcussi FFN. Distribuição da carga hidráulica em linhas de derivação otimizadas por programação linear. Engenharia Agrícola. 2006;26(2):406-414. Portuguese.

9. Rettore Neto $O$, et al. Perda de carga localizada em emissores não coaxiais integrados a tubos de polietileno. Engenharia Agrícola. 2009;29(1):28-39. Portuguese.

10. Howell TA, Hiler EA. Trickle irrigation lateral design. Transactions of the ASAE American Society of Agricultural Engineers. 1974;17:902-908.

11. Howell TA, et al. Design and operation of trickle (drip) systems. In: Jensen, M. E. (Ed.). Design and operation of farm irrigation systems. Michigan: American Society of Agricultural Engineers. 1983;661-717.

12. Wu IP, Yue R. Drip lateral design using energy gradient line approach. Transactions of the ASAE. St Joseph. 1993;36(2):389-3

(c) 2013 Ludwig and Saad; This is an Open Access article distributed under the terms of the Creative Commons Attribution License (http://creativecommons.org/licenses/by/3.0), which permits unrestricted use, distribution, and reproduction in any medium, provided the origin al work is properly cited.

Peer-review history:

The peer review history for this paper can be accessed here: http://www. sciencedomain.org/review-history.php?iid=267\&id=10\&aid=2040 